Research Article

\title{
Genetic Diversity and Population Structure of Moroccan Isolates Belong to Alternaria spp. Causing Black Rot and Brown Spot in Citrus
}

\author{
Lamyaa Zelmat $\mathbb{D}^{1,2,3}$ Joseph Mbasani Mansi $\mathbb{D}^{2,4}$ Sarra Aouzal, ${ }^{2,5}$ Fatima Gaboun, ${ }^{2}$ \\ Slimane Khayi, ${ }^{2}$ Mohammed Ibriz, ${ }^{3}$ Mohammed El Guilli $\mathbb{D}^{1},{ }^{1}$ and Rachid Mentag $\mathbb{D}^{2}$ \\ ${ }^{1}$ Plant Pathology and Postharvest Quality laboratory, Plant Protection Research Unit, Regional Center of Agricultural Research \\ of Kénitra, National Institue of Agricultural Research, El Menzeh Km 9, 14000, Kénitra, Morocco \\ ${ }^{2}$ Biotechnology Research Unit, Regional Center of Agricultural Research of Rabat, National Institute of Agricultural Research, \\ Avenue Ennasr, BP 415 Rabat Principale, 10090, Rabat, Morocco \\ ${ }^{3}$ Department of Biology, Genetics and Biometrics Laboratory, Faculty of Sciences, Ibn Tofail University, Kénitra, Morocco \\ ${ }^{4}$ Department of Biology, Higher Institute of Medical Techniques (ISTM) Kinshasa, Democratic Republic of the Congo \\ ${ }^{5}$ Agro-Food and Health Laboratory, Faculty of Science and Techniques, Hassan First University of Settat, Settat, Morocco
}

Correspondence should be addressed to Mohammed El Guilli; mguilli@yahoo.com and Rachid Mentag; rachidmentag@yahoo.ca

Received 1 April 2021; Revised 21 September 2021; Accepted 12 October 2021; Published 23 November 2021

Academic Editor: Antonio Ferrante

Copyright (c) 2021 Lamyaa Zelmat et al. This is an open access article distributed under the Creative Commons Attribution License, which permits unrestricted use, distribution, and reproduction in any medium, provided the original work is properly cited.

\begin{abstract}
Alternaria alternata is one of the most important fungi causing various diseases on citrus worldwide. In Morocco, Alternaria black rot (ABR) and Alternaria brown spot (ABS) are two major diseases causing serious losses in commercial cultivars of citrus. The aim of the present work was to study the genetic diversity and the population structure of isolates belonging to sect. Alternaria obtained from infected citrus fruits, collected from seven provinces at different locations in Morocco (markets, packinghouses, and orchards). Forty-five isolates were analyzed by sequence-related amplified polymorphism (SRAP) markers, and cluster analysis of DNA fragments was performed using UPGMA method and Jaccard coefficient. Cluster analysis revealed that isolates were classified in four distinct groups. AMOVA revealed also a large extent of variation within sect. Alternaria isolates (99\%). The results demonstrate that no correlation was found among SRAP pattern, host, and geographical origin of these isolates. Population structure analyses showed that the Alternaria isolates from the same collection origin had almost a similar level of admixture.
\end{abstract}

\section{Introduction}

Citrus (Citrus spp., Rutaceae) is one of the most important crops due to its high annual worldwide production. A total of 124 million tons (Mt) was produced in 2016 [1]. Citrus are widely cultivated in over 140 countries around the world [2]. According to USDA [3], Morocco is one of three major producing countries of citrus in the Mediterranean region due to its favorable weather and increased acreage. In 2019, the Moroccan citrus cultivation area reached more than 129,000 ha generating a total production of $2.6 \mathrm{Mt}$ [4]. Nonetheless, this crop is constantly threatened by fungal diseases that cause significant losses either in the field or after harvest leading to important economic impacts.

Alternaria species are considered a major threat to the citrus fruit industry worldwide causing black rot and brown spot diseases during degreening, storage, transportation, and marketing [5-7]. In 2015 and 2016, Alternaria spp. were the most prevalent pathogen causing the diseases of Mandarin fruit in California at $53.5 \%$ and $83.1 \%$, respectively [5]. According to Akimitsu et al. [8], Alternaria brown spot (ABS) is a highly infectious disease of tangerines and their hybrids that occurs worldwide. It causes decrease in productivity and commercial value of fruit [9]. ABR is currently 
considered a serious postharvest problem, since the pathogen can occur abundantly in the central columella of the fruit without any manifestation of external symptoms and can be found in most citrus production areas [10].

Alternaria brown spot of tangerines (ABS) caused by the fungus Alternaria alternata (Fr.) Keissl $[8,11]$ is one of the four major Alternaria diseases affecting susceptible citrus genotypes around the world. The tangerine pathotype produces brown to black lesions on young leaves, twigs, and fruits with or without a chlorotic halo and causes corky lesions on mature fruit $[8,12]$. Alternaria species cause three other diseases in citrus, including Alternaria leaf spot of rough lemon and rangpur lime [13], Alternaria black rot of many citrus cultivars [13], and Mancha foliar of Mexican lime [14]. The ABR pathogen causes black-colored infection developed in the central axis of fruit habitually without any symptoms on the rind surface [7]. The same symptoms have been observed on Citrus sinensis fruits, artificially inoculated with Alternaria alternata [15]. In addition, this pathogen can also produce stem end rot when the fungus pervades into the peel and juice sac of fruit before its harvest and continues to extend outwards later [10]. According to Peever et al. [16], there is a great morphological similarity among the citrus-associated isolates that have a small catenulate spores and that are considered to be distinct pathotypes of the same species, Alternaria alternata. The Alternaria species causing citrus brown spot were identified as belonging to Alternaria alternata and A. arborescens species complexes [17].

To gain insights about Alternaria spp. population circulating in Morocco, genetic diversity studies of the Alternaria pathogen are an important approach to understand its worldwide evolution and determine the population structure of this fungus. In this context, several profiling methods have been widely used to characterize the genetic variability of citrus-associated Alternaria species. These techniques include random amplified polymorphic DNA (RAPD) [18-20], amplified fragment length polymorphism (AFLP) [21, 22], intersimple sequence repeat (ISSR) [23], and restriction fragment length polymorphism (RFLP) [24]. In comparison with other molecular marker techniques, the sequence-related amplified polymorphism (SRAP) is relatively simple and very informative [25]. As demonstrated by [26], it is easier than AFLP markers and more reproducible than RAPD technique. Presently, SRAP markers were used to investigate genetic diversity of different fungi and have been successful for Ganoderma lucidum [27], Sclerotinia sclerotiorum [28], Auricularia auricular [29], Lentinula edodes [30], Tricholoma matsutake [31], Auricularia auricula-judae [32], Rhizoctonia solani [33], and Pyricularia oryzae [34].

Different phylogenetic loci were used to identify the species within Alternaria sect. alternata associated with citrus rots. In particular, the internal transcribed spacer (ITS) has been extensively used [11,35-38], as well as Alternaria major allergen 1 (Alt a1) [15, 39], endopolygalacturonase (endo-PG) [7, 13, 40, 41], SCAR markers (OPA 1-3 and OPA 2-1) [40,41], and the beta-tubulin gene $(\beta$-tub) $[11,20]$.
To date, there is no study reporting the genetic diversity of Moroccan Alternaria in citrus crop. Due to the abundance of Alternaria species in Morocco [42-44] which is being among the important exporters of citrus worldwide, our objectives for this study were (i) to analyze the genetic diversity and population structure of Alternaria spp. isolated from citrus fruit in Morocco using SRAP markers and (ii) to confirm the identity of citrus-associated isolates of Alternaria circulating in Morocco.

\section{Materials and Methods}

2.1. Fungal Isolates. Forty-five isolates of Alternaria spp. were collected from seven provinces in Morocco from markets, packinghouses, and orchards during the period 20172018 (Table 1) (Figure 1). Infected fragments of $5 \mathrm{~mm}$ in diameter were sampled from each Alternaria symptomatic fruit, drenched in a 5\% sodium hypochlorite solution for $2 \mathrm{~min}$, and rinsed in sterilized distilled water. Then, all samples were placed into separate potato dextrose agar medium (PDA) and incubated at $25^{\circ} \mathrm{C}$. The morphological identification of conidia was realized after 3 or 4 days of incubation using a microscope at an objective of 40x. Alternaria sp. colonies were transferred to fresh PDA medium and stored at $4^{\circ} \mathrm{C}$ until use.

2.2. DNA Extraction. For DNA extraction, mycelia were collected in single-spore cultures of the isolates grown in PDA for 7 days at $25^{\circ} \mathrm{C}$. The total DNA was extracted following the modified CTAB method [45]. A total of $50 \mathrm{mg}$ of mycelia was mixed with $1 \mathrm{ml}$ of $\mathrm{CTAB}$ extraction buffer $(0.15 \mathrm{M}$ Tris- $\mathrm{HCl}, 1.05 \mathrm{M} \mathrm{NaCl}, 0.03 \mathrm{M}$ EDTA, $2 \%(w / v) \mathrm{CTAB}$, and $0.02 \%(v / v)$ of $\beta$-mercaptoethanol) and incubated to $65^{\circ} \mathrm{C}$ for 1 hour. A volume of $0.6 \mathrm{ml}$ of chloroform isoamy1 : alcohol $(24: 1-v / v)$ was added, and the mixture was centrifuged at $13000 \mathrm{rpm}$ for $10 \mathrm{~min}$. The supernatant was recovered in a new tube, and DNA precipitated overnight by isopropanol. Finally, the DNA was washed with $200 \mu \mathrm{l}$ of ethanol (75\%) and dissolved with sterile ultrapure water. The purity and quality of extracted DNA were assessed by a spectrophotometer at 230, 260, and $280 \mathrm{~nm}$. For SRAP reactions, the concentration was adjusted to $25 \mathrm{ng} / \mu \mathrm{l}$.

2.3. SRAP Analysis and Polymerase Chain Reaction. SRAPPCR analysis was performed by assessing for polymorphism, 30 combinations of primers (five forward/six reverse) (Table 2), following the protocol described by [26]. The best primer combinations that generated clear polymorphism with reproducible PCR products were used on the 45 DNA samples. All SRAP reactions were prepared at a final volume of $10 \mu \mathrm{l}$ containing $1 \mathrm{U}$ of Taq DNA polymerase, $1 \mathrm{X}$ buffer, $0.5 \mu \mathrm{M}$ of each primer, and $25 \mathrm{ng}$ of DNA template. The amplification of DNA was programmed with an initial denaturation at $94^{\circ} \mathrm{C}$ for $5 \mathrm{~min}$ followed by 5 cycles with denaturation, annealing, and extension, respectively, at $94^{\circ} \mathrm{C}, 35^{\circ} \mathrm{C}$, and $72^{\circ} \mathrm{C}$ for $1 \mathrm{~min}$ for each step. Then, 35 cycles were added with the annealing temperature set at $50^{\circ} \mathrm{C}$. The PCR products were analyzed on polyacrylamide gel stained by ethidium bromide and visualized using UV transilluminator. 
TABLE 1: Isolates of Alternaria spp. obtained from citrus fruits during 2017-2018.

\begin{tabular}{|c|c|c|c|c|c|}
\hline Isolate & Host & Date & Province/site & Location (GPS) & $\begin{array}{c}\text { Accession } \\
\text { number }\end{array}$ \\
\hline A3 & Oranges & December, 2017 & Kénitra/orchard & $\begin{array}{c}\mathrm{N} 34^{\circ} 30^{\prime} 52,964^{\prime \prime} \mathrm{W} 6^{\circ} 18^{\prime} \\
3,789^{\prime \prime}\end{array}$ & MW575592 \\
\hline Elm 1 & Oranges & March. 2018 & Kénitra/orchard & $\begin{array}{c}\mathrm{N} 34^{\circ} 17^{\prime} 38,99^{\prime \prime} \mathrm{W} 6^{\circ} 29^{\prime} \\
3,97^{\prime \prime}\end{array}$ & MW616575 \\
\hline Elm2 & Oranges & March. 2018 & Kénitra/orchard & $\begin{array}{c}\mathrm{N} 34^{\circ} 17^{\prime} 38,99^{\prime \prime} \mathrm{W} 6^{\circ} 29^{\prime} \\
3,97^{\prime \prime}\end{array}$ & - \\
\hline $\mathrm{K} 1, \mathrm{~K} 2, \mathrm{~K} 3, \mathrm{~K} 4, \mathrm{~K} 6$ & Oranges & March, 2018 & Kénitra/market & $\begin{array}{c}\mathrm{N} 34^{\circ} 14^{\prime} 59,18^{\prime \prime} \mathrm{W} 6^{\circ} 32^{\prime} \\
58,14^{\prime \prime}\end{array}$ & - \\
\hline K5 & Oranges & March, 2018 & Kénitra/market & $\begin{array}{c}\mathrm{N} 34^{\circ} 14^{\prime} 59,18^{\prime \prime} \mathrm{W} 6^{\circ} 32^{\prime} \\
58,14^{\prime \prime}\end{array}$ & MW616574 \\
\hline $\mathrm{El} 2$ & Mandarins & February, 2018 & Kénitra/orchard & $\begin{array}{c}\mathrm{N} 34^{\circ} 17^{\prime} 38,99^{\prime \prime} \mathrm{W} 6^{\circ} 29^{\prime} \\
3,97^{\prime \prime}\end{array}$ & - \\
\hline G1, G2, G3, G4, G6, G7, G8, G9, G10 & Lemons & March, 2018 & Kénitra/market & $\begin{array}{c}\mathrm{N} 34^{\circ} 15^{\prime} 16,315^{\prime \prime} \mathrm{W} 6^{\circ} 36^{\circ} \\
58,09^{\prime \prime}\end{array}$ & - \\
\hline G5 & Lemons & March, 2018 & Kénitra/market & $\begin{array}{c}\mathrm{N} 34^{\circ} 15^{\prime} 16,315^{\prime \prime} \mathrm{W} 6^{\circ} 36^{\circ} \\
58,09^{\prime \prime}\end{array}$ & MW616570 \\
\hline $\mathrm{I} 2$ & Lemons & January, 2018 & Kénitra/market & $\begin{array}{c}\mathrm{N} 33^{\circ} 46^{\prime} 43,42^{\prime \prime} \mathrm{W} 6^{\circ} 7^{\prime} \\
23,34^{\prime \prime}\end{array}$ & MW616569 \\
\hline I3 & Lemons & January, 2018 & Kénitra/market & $\begin{array}{c}\mathrm{N} 33^{\circ} 46^{\prime} 43,42^{\prime \prime} \mathrm{W} 6^{\circ} 7^{\prime} \\
23,34^{\prime \prime}\end{array}$ & - \\
\hline Kh3 & Lemons & April, 2018 & Khémisset/market & $\begin{array}{c}\mathrm{N} 33^{\circ} 49^{\prime} 31,824^{\prime \prime} \mathrm{W} 6^{\circ} 4^{\prime} \\
20,303^{\prime \prime}\end{array}$ & - \\
\hline Kh6 & Oranges & April, 2018 & Khémisset/market & $\begin{array}{c}\mathrm{N} 33^{\circ} 49^{\prime} 31,824^{\prime \prime} \mathrm{W} 6^{\circ} 4^{\prime} \\
20,303^{\prime}\end{array}$ & - \\
\hline Sa1 & Lemons & April, 2018 & Salé/market & $\begin{array}{c}\mathrm{N} 34^{\circ} 2^{\prime} 56,81^{\prime \prime} \mathrm{W} 6^{\circ} 47^{\prime} \\
23,01^{\prime \prime}\end{array}$ & - \\
\hline $\mathrm{Sa} 2$ & Oranges & April, 2018 & Salé/market & $\begin{array}{c}\mathrm{N} 34^{\circ} 2^{\prime} 56,81^{\prime \prime} \mathrm{W} 6^{\circ} 47^{\prime} \\
23,01^{\prime \prime}\end{array}$ & - \\
\hline $\mathrm{Sd} 2$ & Oranges & March, 2018 & $\begin{array}{l}\text { Sidi Slimane/ } \\
\text { market }\end{array}$ & $\begin{array}{c}\mathrm{N} 34^{\circ} 16^{\prime} 1,476^{\prime \prime} \mathrm{W} 5^{\circ} 55^{\prime} \\
30,732^{\prime \prime}\end{array}$ & MW616571 \\
\hline Sds2, Sds9, Sds10 & Oranges & April, 2018 & $\begin{array}{l}\text { Sidi Slimane/ } \\
\text { market }\end{array}$ & $\begin{array}{c}\mathrm{N} 34^{\circ} 16^{\prime} 1,476^{\prime \prime} \mathrm{W} 5^{\circ} 55^{\prime} \\
30,732^{\prime \prime}\end{array}$ & \\
\hline Sds8 & Oranges & April, 2018 & $\begin{array}{l}\text { Sidi Slimane/ } \\
\text { market }\end{array}$ & $\begin{array}{c}\mathrm{N} 34^{\circ} 16^{\prime} 1,476^{\prime \prime} \mathrm{W} 5^{\circ} 55^{\prime} \\
30,732^{\prime \prime}\end{array}$ & MW616567 \\
\hline Sds6 & Oranges & April, 2018 & $\begin{array}{l}\text { Sidi Slimane/ } \\
\text { market }\end{array}$ & $\begin{array}{c}\mathrm{N} 34^{\circ} 16^{\prime} 1,476^{\prime \prime} \mathrm{W} 5^{\circ} 55^{\prime} \\
30,732^{\prime \prime}\end{array}$ & MW616573 \\
\hline La5 & Mandarins & January, 2018 & $\begin{array}{c}\text { Larache/ } \\
\text { packinghouse }\end{array}$ & $\begin{array}{c}\mathrm{N} 35^{\circ} 0^{\prime} 7,08^{\prime \prime} \mathrm{W} 6^{\circ} 11^{\prime} \\
58,23^{\prime \prime}\end{array}$ & - \\
\hline La1 & Mandarins & January, 2018 & $\begin{array}{c}\text { Larache/ } \\
\text { packinghouse }\end{array}$ & $\begin{array}{c}\mathrm{N} 35^{\circ} 0^{\prime} 7,08^{\prime \prime} \mathrm{W} 6^{\circ} 11^{\prime} \\
58,23^{\prime \prime}\end{array}$ & MW616572 \\
\hline Ag3, Ag12 & Oranges & May, 2018 & Agadir/market & $\begin{array}{c}\mathrm{N} 30^{\circ} 24^{\prime} 44,37^{\prime \prime} \mathrm{W} 9^{\circ} 34^{\prime} \\
48,63^{\prime \prime}\end{array}$ & - \\
\hline Ag18, Ag22, Ag23, Ag24, Ag25, Ag26 & Oranges & July, 2018 & Agadir/market & $\begin{array}{c}\mathrm{N} 30^{\circ} 24^{\prime} 44,37^{\prime \prime} \mathrm{W} 9^{\circ} 34^{\prime} \\
48,63^{\prime \prime}\end{array}$ & - \\
\hline
\end{tabular}


TABLE 1: Continued.

\begin{tabular}{|c|c|c|c|c|c|}
\hline Isolate & Host & Date & Province/site & Location (GPS) & $\begin{array}{c}\text { Accession } \\
\text { number }\end{array}$ \\
\hline Ag21 & Oranges & July, 2018 & Agadir/market & $\begin{array}{c}\mathrm{N} 30^{\circ} 24^{\prime} 44,37^{\prime \prime} \mathrm{W} 9^{\circ} 34^{\prime} \\
48,63^{\prime \prime}\end{array}$ & MW616576 \\
\hline Bn1 & Oranges & April, 2018 & Beni Mellal/market & $\begin{array}{c}\mathrm{N} 32^{\circ} 20^{\prime} 40,469^{\prime \prime} \mathrm{W} 6^{\circ} 20^{\prime} \\
45,653^{\prime \prime}\end{array}$ & - \\
\hline E3 & Clementines & December, 2017 & $\begin{array}{l}\text { Beni Mellal/ } \\
\text { packinghouse }\end{array}$ & $\begin{array}{c}\mathrm{N} 32^{\circ} 20^{\prime} 40,469^{\prime \prime} \mathrm{W} 6^{\circ} 20^{\prime} \\
45,653^{\prime \prime}\end{array}$ & MW616568 \\
\hline
\end{tabular}

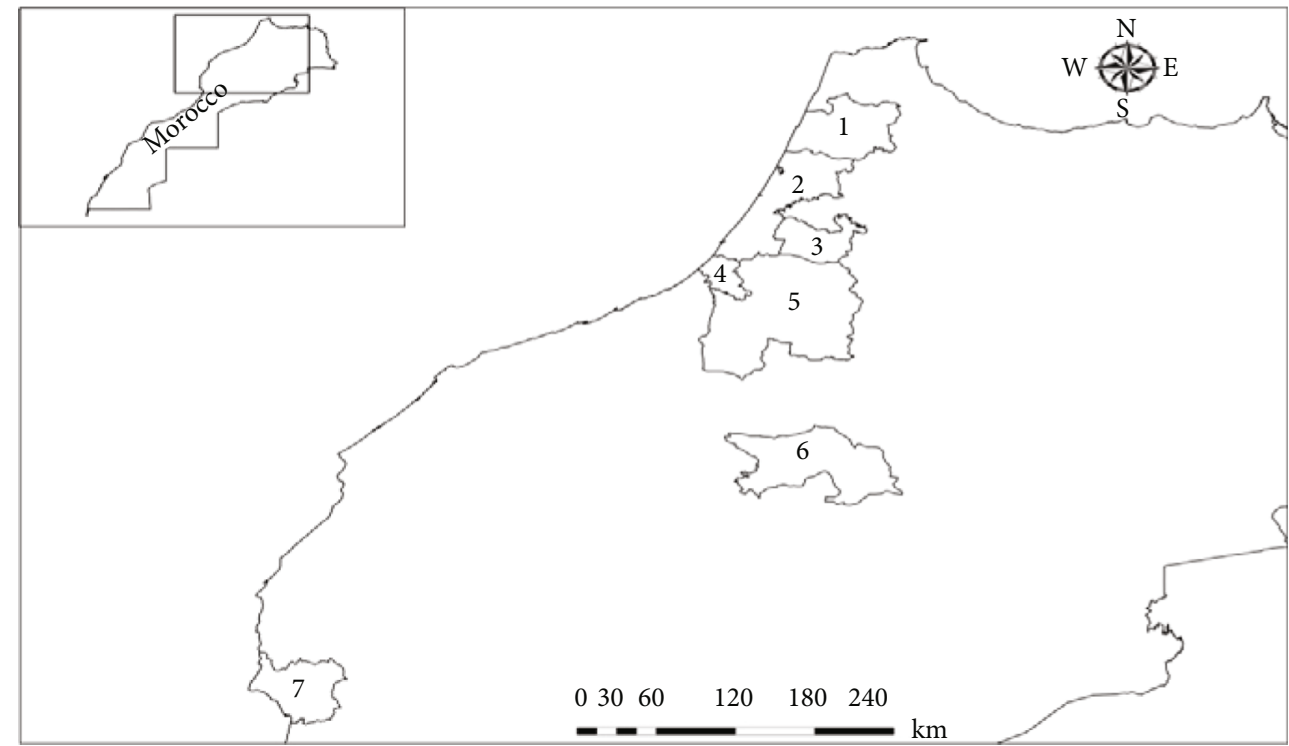

FIGURE 1: Geographic locations of the seven provinces where Alternaria sp. isolates were collected: 1-Larache, 2-Kénitra, 3-Sidi Slimane, 4-Salé, 5-Khémisset, 6-Beni Mellal, and 7-Agadir.

TABLE 2: Forward and reverse sequences of SRAP primers used in this study.

\begin{tabular}{lccc}
\hline Forward primer names & Sequences & Reverse primer names & \multicolumn{1}{c}{ Sequences } \\
\hline ME1 & $5^{\prime}$-TGAGTCCAAACCGGATA-3' & EM1 & $5^{\prime}$-GACTGCGTACGAATTAAT-3 \\
ME2 & $5^{\prime}$-GAGTCCAAACCGGAGC-3 & EM2 & $5^{\prime}$-GACTGCGTACGAATTTGC-3 \\
ME3 & $5^{\prime}$-TGAGTCCAAACCGGAAT-3' & EM3 & $5^{\prime}$-GACTGCGTACGAATTGAC-3' \\
ME4 & $5^{\prime}$-TGAGTCCAAACCGGACC-3' & EM4 & $5^{\prime}$-GACTGCGTACGAATTTGA-3' \\
ME5 & $5^{\prime}$-TGAGTCCAAACCGGAAG-3' & EM5 & $5^{\prime}$-GACTGCGTACGAATTAAC-3' \\
& & EM6 & $5^{\prime}$-GACTGCGTACGAATTGCA-3'
\end{tabular}

2.4. Molecular Phylogeny. To ascertain the identity of the fungal isolates, 11 representative Alternaria strains (Elm1, A3, K5, G5, E3, I2, Sds6, La1, Sd2, Ag21, and, Sds8) were selected from our collection for molecular identification. Internal transcribed spacer (ITS) region of rDNA was amplified. PCR products were Sanger sequenced (Secugen, Madrid, Spain). To perform the phylogenetic analysis, ITS sequences of reference strains were retrieved from GenBank and used (Table 3). Multiple sequence alignment of the ITS sequences was conducted using ClustalW, and the phylogenetic tree was inferred using the neighbour-joining method
[46] with 1000 bootstrap replications. Analyses were conducted in MEGA version X [47].

2.5. Statistical Analyses. The molecular data of variability were scored for the presence or absence of the amplification profile for each primer combination, respectively, as 1 or 0 . Efficiency of SRAP markers was evaluated with the polymorphism rates of primers and polymorphism information content (PIC). The PIC was calculated as $2 f_{i}$ $\times\left(1-f_{i}\right)$, where $f_{i}$ is the frequency of band presence for locus $I$ [48]. 
TABle 3: Reference strains of Alternaria spp. used in this study and their accession numbers.

\begin{tabular}{lccc}
\hline Species & Strain & Host/origin & GenBank accession number (ITS) \\
\hline A. arborescens & CBS 109730 & Tomato & FM958522 \\
& MAP05a & Triticum, grain & FM958521 \\
A. alternata & CBS 117130 & Potted strawberry tree & FM958520 \\
& CBS 117143 & Capsicum annuum, fruit & FM958519 \\
& CBS 154.31 & Staphylea trifolia & FN668745 \\
& MAP02 & Triticum, grain & FN668752 \\
A. tenuissima & MAP09 & Triticum, grain & FN668744 \\
& MAP01 & Triticum, grain & FN668750 \\
& MAP07 & Triticum, grain & FN668753 \\
A. dauci & MAP10 & Triticum, grain & FN668749 \\
A. solani & MAP06 & Triticum, grain & FM958531 \\
A. gaisen & CBS 880.95 & Fragaria vesca & FM958524 \\
A. longipes & CBS 101592 & Carrot seeds & FM958530 \\
A. porri & CBS 347.79 & Tomato, fruit & FM958525 \\
A. radicina var. radicina & CBS 632.93 & Pyrus pyrifolia, leaf & FM958527 \\
\hline
\end{tabular}

The percentage of polymorphic loci, heterozygosity, and Shannon's information index were calculated for the genetic diversity analysis using GenAlEX version 6.5 [49]. Molecular variance analysis (AMOVA) was performed to determine the genetic variance within and among isolates according to their geographic origins [50]. Based on the Jaccard dissimilarity coefficient, the dendrogram was constructed using DARwin version 6 [51] and employing the unweighted pair group method with an arithmetic average (UPGMA) cluster analysis.

STRUCTURE software v.2.3.4 [52] and Bayesian distinct Monte Carlo Markov Chain (MCMC) algorithm were used in this study to identify the population structure of Alternaria spp. isolates from citrus fruits. Each simulation considered in 10,000 iterations after a length burning period of 1,000 . The true number of clusters $(K)$ of the admixture test was estimated, afterward, from the Structure Harvester web tool [53].

\section{Results}

3.1. SRAP Analysis. A total of 30 primer combinations were initially tested for SRAP analysis. The result allowed to select six primer combinations showing the highest polymorphism (ME2/EM6, ME4/EM6 ME5/EM2, ME5/EM6, ME2/EM3, and ME3/EM6). The total number of bands generated by each primer varied from 10 (ME3/EM6) to 32 (ME2/EM6) with an average of 22.3. The polymorphism rate ranged from 99.3 to $100 \%$, with an average of $99 \%$ of number of polymorphic bands (Table 4). The PIC values varied from 0.22 (ME3/EM6) to 0.35 (ME5/EM2).

3.2. Genetic Diversity. According to SRAP marker analysis, the results revealed various levels of genetic diversity indices
TABLE 4: Analysis of SRAP primer combinations results.

\begin{tabular}{lcccc}
\hline $\begin{array}{l}\text { SRAP } \\
\text { primers }\end{array}$ & $\begin{array}{c}\text { Total number } \\
\text { of bands }\end{array}$ & $\begin{array}{c}\text { Number of } \\
\text { polymorphic } \\
\text { bands }\end{array}$ & $\begin{array}{c}\text { Polymorphism } \\
\text { rate (\%) }\end{array}$ & $\begin{array}{c}\text { PIC } \\
\text { values }\end{array}$ \\
\hline ME2/EM6 & 32 & 32 & 100 & 0.30 \\
ME4/EM6 & 15 & 14 & 93,33 & 0.26 \\
ME5/EM2 & 26 & 26 & 100 & 0.35 \\
ME5/EM6 & 26 & 26 & 100 & 0.27 \\
ME2/EM3 & 25 & 25 & 100 & 0.29 \\
ME3/EM6 & 10 & 10 & 100 & 0.22 \\
Total & 134 & 133 & - & - \\
Mean & 22.3 & 22.2 & 99 & 0.28 \\
\hline
\end{tabular}

(Table 5). The percentage of polymorphic loci within populations varied from 15.67 to $94.03 \%$, in Larache and Kénitra populations, respectively. The highest values of Shannon's information index $(I)$, expected heterozygosity $(\mathrm{He})$, number of different alleles (Na), and number of effective alleles $(\mathrm{Ne})$ were observed in Kénitra, with $0.41,0.26,1.89$, and 1.44 , respectively, while the lowest values were observed in Larache with $0.09,0.06,0.62$, and 1.11, respectively.

3.3. Genetic Distance. The genetic distance was calculated to determine the similarity among the isolates based on their geographical origin. The results revealed that the genetic distance was very low between Kénitra and Sidi Slimane populations (0.030), while it was very high between Salé and Khemisset, Salé and Sidi Slimane, then between Larache and Beni Mellal (0.212) (Table 6). Molecular variance analysis (AMOVA) was performed to estimate genetic differentiation among populations and within populations (PhiPT). Accordingly, AMOVA test showed the highest genetic 
TABLE 5: Summary of genetic diversity indices of Alternaria isolates collected from seven provinces of Morocco based on SRAP marker.

\begin{tabular}{lccccc}
\hline Pop & $P(\%)$ & $\mathrm{Na}$ & $\mathrm{Ne}$ & $I$ & $\mathrm{He}$ \\
\hline Kénitra & 94.03 & 1.896 & 1.441 & 0.410 & 0.266 \\
Khémisset & 61.94 & 1.313 & 1.370 & 0.330 & 0.219 \\
Salé & 25.37 & 0.806 & 1.179 & 0.153 & 0.105 \\
Sidi Slimane & 70.90 & 1.455 & 1.363 & 0.339 & 0.220 \\
Agadir & 71.64 & 1.455 & 1.435 & 0.370 & 0.248 \\
Larache & 15.67 & 0.627 & 1.111 & 0.095 & 0.065 \\
Beni Mellal & 33.58 & 0.873 & 1.237 & 0.203 & 0.139 \\
Mean & 53.30 & 1.204 & 1.305 & 0.271 & 0.180 \\
\hline
\end{tabular}

P (\%): percentage of polymorphic loci; Na: number of different alleles; Ne: number of effective alleles; I: Shannon's information index; He: expected heterozygosity.

variation within populations (99\%), whereas the level of interpopulation variation was only $1 \%$ (Table 7 ).

3.4. Cluster Analysis. UPGMA cluster analysis of SRAP data, using Jaccard coefficient, revealed four distinct groups at $60 \%$ dissimilarity mean level, with a maximum of $86 \%$ and a minimum of $25 \%$. The dendrogram illustrated in Figure 2 showed that the first group included 5 isolates originating from Khémisset, Sidi Slimane, Agadir, and Kénitra. The second group accommodated 11 isolates obtained from Khémisset, Agadir, Kénitra, Salé, and Larache. The third contained 16 isolates and obtained from Agadir, Kénitra, Salé, Larache, and Beni Mellal. The last group included 13 isolates collected from Khémisset, Sidi Slimane, Agadir, Kénitra, and Beni Mellal. Considering the genetic variability between the 45 isolates studied, no correlation was shown with their geographic location or their host plant.

3.5. Population Structure. The Alternaria isolates were genetically structured using the STRUCTURE software. The true number of clusters $(K)$ was identified based on the Bayesian approach. Structure Harvester web tool findings indicated that the highest value of delta $K$ equals 3 . The Bayesian cluster analysis revealed, afterward, four main groups with the best identified $K$ value (Figure 3 ). Each colored column represented an individual isolate of Alternaria population. The isolates from the same collection origin had almost a similar level of admixture and were assigned in the same genetic group. However, Kénitra individuals were classified in two different groups, while the most isolates from Khémisset and Sale were assigned in the third group. The isolates from Sidi Slimane, Agadir, Larache, and Beni Mellal provinces were assigned in the last.

3.6. Molecular Phylogeny. Phylogenetic tree generated using ITS sequences highlighted four distinct clades with high bootstrap value support (1000) (Figure 4). The topology positioned the 11 Alternaria isolates from citrus within Clade I with five other references strains for Alternaria isolates obtained from citrus with five other reference strains for Alternaria alternata, A. tenuissima, A. arborescens, A. gaisen, and $A$. longipes. Clade II includes the only $A$. radicina strain. Alternaria porri, A. dauci, and A. solani formed Clade III, while Lewia infectoria constitute the last Clade.

\section{Discussion}

Sequence-related amplified polymorphism (SRAP) is an adequate molecular marker widely used to assess the genetic diversity in plants and fungi $[32,34,54-56]$. Compared to other molecular markers, SRAP is the simplest and the most reproducible technique of genome-wide fragments and remains an inexpensive and highly variable method [57]. It is generally used to construct the genetic map and analysis of genetic diversity and to compare genomes [58]. Many recent studies have used the SRAP technique to analyze the genetic diversity of different fungal pathogens. Tripathi and Dubey [33] studied the genetic diversity of 89 isolates of Rhizoctonia solani infecting pulse crops in India, using this molecular marker. Longya et al.[34] used both SRAP and ISSR markers to examine the genetic variation of 59 rice blast fungus strains, Pyricularia oryzae, in Thailand.

In the present study, SRAP marker was used to evaluate the level of genetic diversity within and among 45 isolates of Alternaria spp. obtained from Moroccan citrus. The results indicates a total of 133 of polymorphic bands generated by six primer combinations with an average of 22.16 bands per primer combination. The mean polymorphism rate (99\%) and Shannon's index (0.27) confirmed also high levels of genetic diversity of the isolates. The same pattern was reported by [18], who observed high genetic diversity among 45 isolates of $A$. alternata from citrus in southern Iran, based on RAPD markers using eight primers. The average of amplified bands was 27.12. Furthermore, the Brazilian isolates of A. alternata collected from Tangerine were characterized based on ISSR markers and 20 polymorphic bands, the isolates revealing low genetic variability in three groups and high diversity only in last group [23].

Several research used the Polymorphism Information Content Values (PICv) to assess the genetic diversity among species. According to [59], the high, medium, or low locus polymorphism is compatible, respectively, with, $\mathrm{PIC}>0.5$, $0.5>$ PIC $>0.25$, and PIC $<0.25$. In present study, the PICv ranged from 0.22 to 0.35 with an average value of 0.28 . Six values of PIC exceeded 0.25 , and only one was less than 0.25 . These results showed that the SRAP markers are an efficient tool to determine the level of genetic diversity of Alternaria isolates.

The dendrogram constructed in this study using the UPGMA method distinguished four main groups, based on the molecular diversity of isolates and their geographic origins. The clustering results showed no significant correlation between the genetic variability of Alternaria isolates and their distribution in Morocco. These results are in accordance with [22] who assessed the genetic diversity of $A$. alternata populations sampled from tangerines in Italy and reported that there was no correlation between geographical origin, host, and year of isolation. In another study, a slight effect of host plant and geographical location on genetic variation in A. alternata obtained from seeds of Amaranthus was observed using the RAPD technique [60]. As described 
TABle 6: Pairwise population matrix of Nei genetic distance.

\begin{tabular}{|c|c|c|c|c|c|c|c|}
\hline & Kénitra & Khémisset & Salé & Sidi Slimane & Agadir & Larache & Beni Mellal \\
\hline Kénitra & 0.000 & & & & & & \\
\hline Khémisset & 0.042 & 0.000 & & & & & \\
\hline Salé & 0.159 & 0.212 & 0.000 & & & & \\
\hline Sidi Slimane & 0.030 & 0.041 & 0.212 & 0.000 & & & \\
\hline Agadir & 0.033 & 0.060 & 0.158 & 0.041 & 0.000 & & \\
\hline Larache & 0.132 & 0.162 & 0.153 & 0.169 & 0.127 & 0.000 & \\
\hline Beni Mellal & 0.109 & 0.106 & 0.210 & 0.092 & 0.114 & 0.212 & 0.000 \\
\hline
\end{tabular}

TABLE 7: Analyses of molecular variance (AMOVA) for Alternaria isolates by SRAP markers.

\begin{tabular}{lcccccc}
\hline Source & Df & SS & MS & Est. var. & $\%$ & PhiPT \\
\hline Among populations & 6 & 128,147 & 21,358 & 0.175 & $1 \%$ & 0.009 \\
Within populations & 38 & 774,431 & 20,380 & 20,380 & $99 \%$ & 0.414 \\
Total & 44 & 902,578 & & 20,555 & $100 \%$ & \\
\hline
\end{tabular}

Df: degree of freedom; SS: sums of squares; MS: mean squares; Est. var: estimate of variance; \%: percentage of total variation; PhiPT: phi-statistics probability level after 999 permutations; $P$ is based on 999 permutations.

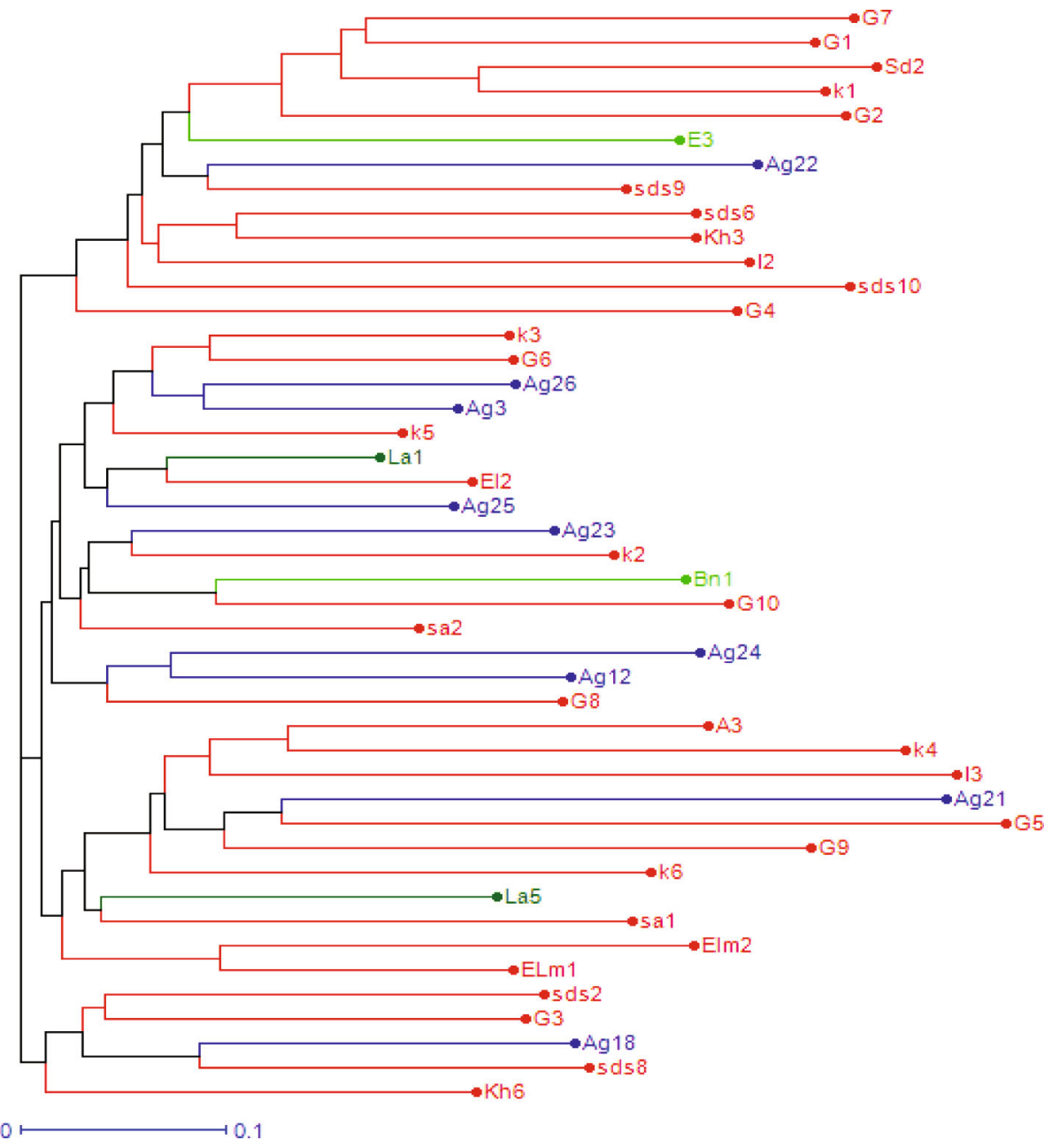

FIgURE 2: Dendrogram of 45 Alternaria isolates from Citrus collected from seven provinces in Morocco. Unweighted pair group method with arithmetic mean (UPGMA) cluster analysis was based on Jaccard's coefficient. A3, Elm1, Elm2, K1, K2, K3, K4, K6, K5, Kh6, Sa2, Sd2, Sds2, Sds9, Sds10, Sds8, Sds6, Ag3, Ag12, Ag18, Ag22, Ag23, Ag24, Ag25, Ag26, Ag21, and Bn1—oranges; El2, La5, and La1— Mandarins; G1, G2, G3, G4, G6, G7, G8, G9, G10, G5, I2, I3, Kh3, and Sa1-lemons; E3-clementines. 


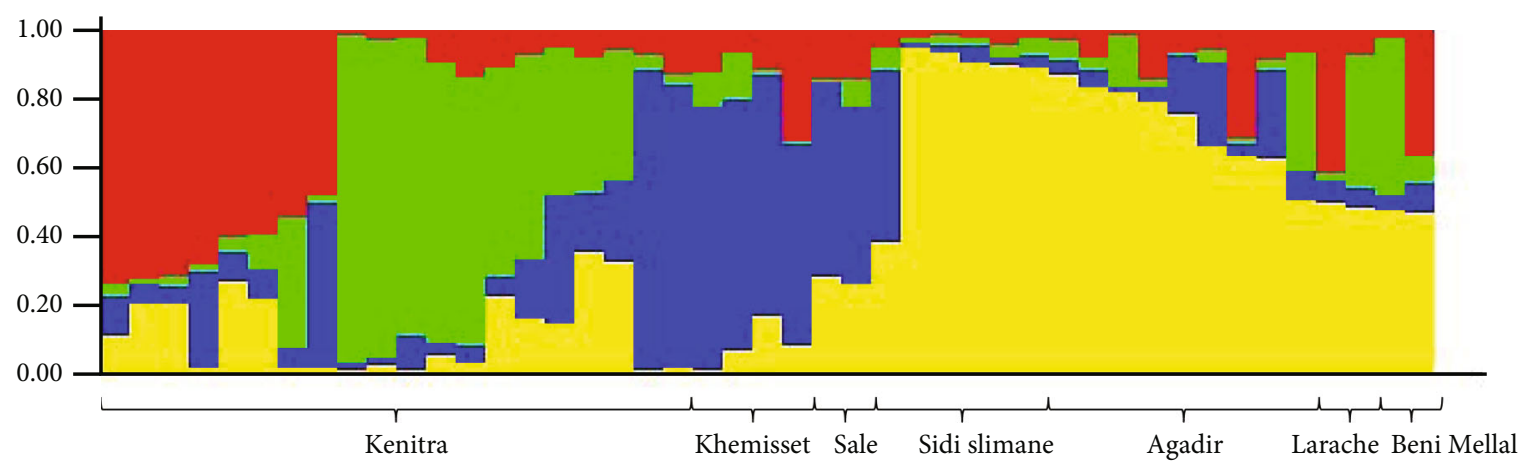

FIgURE 3: Genetic assignment of the Alternaria populations using the STRUCTURE program at $K=3$ and Bayesian method.

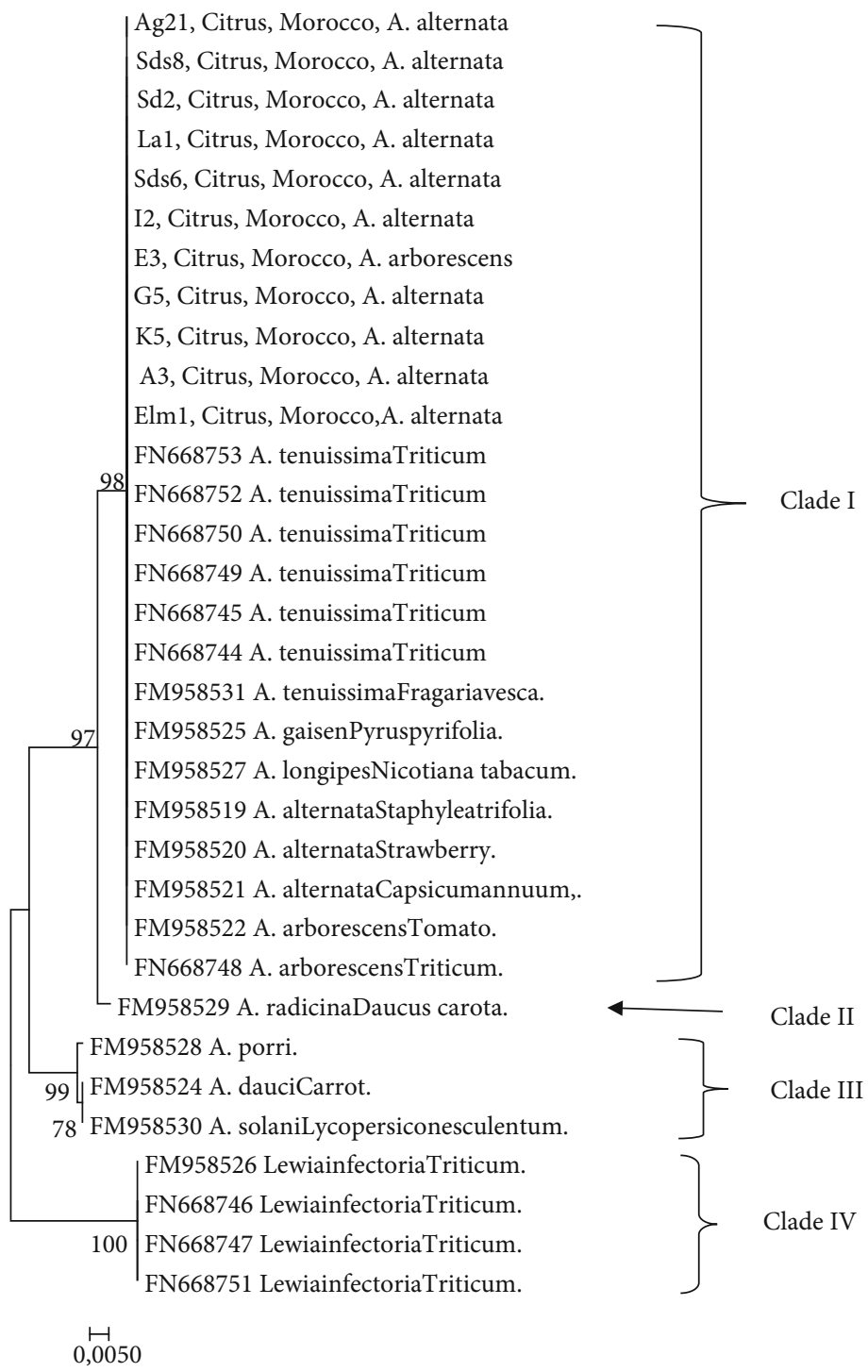

FIGURE 4: Phylogenetic tree based on the internal transcribed spacer (ITS) sequences of 11 isolates of Alternaria spp. obtained from citrus fruit. The bootstrap value support is indicated in the branches.

by [61], the absence of relationship among the origin and molecular diversity of this collection was likely attributable to the great mobility and the uniform dispersal by wind of A. alternata spores, which can cover enormous distances.
In contrast, other works reported that the genetic diversity of A. alternata collected from Citrus [19] and potatoes [62] was dependent on their sampled locations, hosts, or year of isolation. Additionally, [63] detected a high level of 
molecular diversity among A. solani originating from the same field of potatoes in Germany.

Our findings of AMOVA test showed the highest genetic variation within populations (99\%), whereas the level of interpopulation variation was only $1 \%$. This is in accordance with [64] who observed that the variation within Australian populations of $A$. brassicicola (86\%) was higher than among them (14\%). In another study, [65] found high genetic variation within $A$. alternata from Pinus tabulaeformis detected by random amplified microsatellites (RAMS). The results showed that there was no correlation between the fungal genotypes and host tissue. Furthermore, [66] detect high genetic diversity within populations of $A$. solani in China using SSR markers.

The phylogeny analysis results showed that all the 11 Alternaria isolates of the present study selected were assembled with five other strains of Alternaria used as references. In particular, the ITS sequences of Alternaria species isolated from citrus were identical to those of A. alternata, A. tenuissima, A. arborescens, A. gaisen, and A. longipes. This result is in accordance with the finding in [16], which reported a similarity among nine Alternaria isolates from citrus and seven other species including $A$. alternata, A. longipes, $A$. infectoria, A. tenuissima, A. gaisen, A. arborescens, and A. mali based on MtLSU phylogenies. In another study, Armitage et al. [39] based on sequencing of five phylogenetic loci (endo-PG, Alt a1, TMA22, PGS1, and REV3) and morphological analysis reported that the citrus-associated strains of Alternaria studied were grouped with $A$. alternata, A. tenuissima, and $A$. mali (EGS references). Their findings indicated that $A$. alternata subsp. arborescens, A. alternata subsp. gaisen, and $A$. alternata subsp. tenuissima were considered subspecies within the $A$. alternata species group. In addition, among twenty isolates of Alternaria spp. collected from citrus, eighteen were referable to $A$. alternata CBS references and two referable to $A$. arborescens CBS references based on the ITS and endo-PG sequencing [11]. These authors found a higher variability within $A$. alternata species when the phylogenetic analysis is based on endo-PG, ITS, $\beta$-tub, and SCAR marker (OPA1-3 and OPA2-1) sequences.

\section{Conclusion}

The present study concerned the assessment of genetic differentiation of Alternaria isolates originating from seven provinces in Morocco. SRAP markers revealed high polymorphism rate with an average of 99\%. Furthermore, AMOVA results demonstrate that the level of genetic diversity was higher within the Moroccan Alternaria populations (99\%) than among them (1\%). Cluster analysis constructed according to the genetic diversity of the isolates and their distribution generated four distinct groups. These findings indicate that SRAP markers could be an adequate method to be used for genetic structure and molecular differentiation studies among and within Alternaria populations. Molecular identification by sequencing of the ITS region confirmed that the selected Moroccan strains belong to the A. alternata species complex. The reported knowledge of genetic diversity and population structure in this study furthers our understanding of the Alternaria pathogens on citrus. This provides importance for selecting the resistance citrus cultivars and reduces, furthermore, the pre- and postharvest losses caused by species of Alternaria sect. alternata. The collection from other provinces in Morocco could be appropriate to evaluate the variability of Alternaria on a large scale.

\section{Data Availability}

Accessions Nos. MW575592, MW616575, MW616574, MW616570, MW616569, MW616571, MW616567, MW616573, MW616572, MW616576, and MW616568 are already available in NCBI.

\section{Conflicts of Interest}

The authors declare that they have no conflicts of interest.

\section{Acknowledgments}

This study was supported by the grant from KAFACI (Project Number: KAH 20180108), Rural Development Administration of Korea, the National Institute of Agricultural Research of Morocco, and Ministère de l'Enseignement Supérieur, de la Recherche Scientifique et de la Formation des Cadres (MESRSFC) through funding of INTOMED project within the Mediterranean PRIMA program.

\section{References}

[1] FAO, Processed Statistical Bulletin 2016, Food and Agriculture Organization of the United Nations, Rome, Italy, 2017.

[2] Y. Chen, "Citrus, Integrated Processing Technologies for Food and Agricultural By-Products," in pp. 217-242, Elsevier, 2019.

[3] Citrus: World Markets and Trade, United States Department of Agriculture, 2019.

[4] M. Citrus, 2020, http://maroc-citrus.com/statistiques-2/.

[5] S. Saito and C. Xiao, "Prevalence of postharvest diseases of mandarin fruit in California," Plant Health progress, vol. 18, no. 4, pp. 204-210, 2017.

[6] N. Akhtar, T. Anjum, and R. Jabeen, "Isolation and identification of storage fungi from citrus sampled from major growing areas of Punjab, Pakistan," International Journal of Agriculture and Biology, vol. 15, no. 6, 2013.

[7] T. Peever, L. Carpenter-Boggs, L. W. Timmer, L. M. Carris, and A. Bhatia, "Citrus black rot is caused by phylogenetically distinct lineages of Alternaria alternata," Phytopathology, vol. 95, no. 5, pp. 512-518, 2005.

[8] K. Akimitsu, T. L. Peever, and L. Timmer, "Molecular, ecological and evolutionary approaches to understanding Alternaria diseases of citrus," Molecular Plant Pathology, vol. 4, no. 6, pp. 435-446, 2003.

[9] R. F. Reis, T. F. de Almeida, E. S. Stuchi, and A. de Goes, "Susceptibility of citrus species to Alternaria alternata, the causal agent of the Alternaria brown spot," Scientia Horticulturae, vol. 113, no. 4, pp. 336-342, 2007.

[10] L. Palou and J. L. Smilanick, Postharvest Pathology of Fresh Horticultural Produce, CRC Press, 2019. 
[11] F. Garganese, L. Schena, I. Siciliano et al., "Characterization of citrus-associated Alternaria species in Mediterranean areas," PloS one, vol. 11, no. 9, article e0163255, 2016.

[12] F. A. Azevedo, I. Martelli, D. Polydoro, C. Pacheco, E. Schinor, and M. Bastianel, "Positive relationship between citrus leaf miner and Alternaria brown spot," Ciência Rural, vol. 45, no. 7, pp. 1160-1163, 2015.

[13] L. W. Timmer, K. Akimitsu, Z. V. Solel, and T. L. Peever, "Alternaria diseases of citrus-novel pathosystems," Phytopathologia Mediterranea, vol. 42, no. 2, pp. 99-112, 2003.

[14] A. Masunaka, K. Ohtani, T. L. Peever et al., "An isolate of Alternaria alternata That is pathogenic to both tangerines and rough lemon and produces two host-selective toxins, ACT- and ACR-toxins," Phytopathology, vol. 95, no. 3, pp. 241-247, 2005.

[15] M. F. Gabriel, N. Uriel, F. Teifoori, I. Postigo, E. Suñén, and J. Martínez, "The major Alternaria alternata allergen, Alt a 1: A reliable and specific marker of fungal contamination in citrus fruits," International Journal of Food Microbiology, vol. 257, pp. 26-30, 2017.

[16] T. L. Peever, G. Su, L. Carpenter-Boggs, and L. W. Timmer, "Molecular systematics of citrus-associated Alternaria species," Mycologia, vol. 96, no. 1, pp. 119-134, 2004.

[17] F. Garganese, A. Ippolito, V. di Rienzo, C. Lotti, C. Montemurro, and S. M. Sanzani, "A new high-resolution melting assay for genotyping Alternaria species causing citrus brown spot," Journal of the Science of Food and Agriculture, vol. 98, no. 12, pp. 4578-4583, 2018.

[18] M. Ghasemloee and A. R. Niazmand, "Genetic diversity of Alternaria alternata associated with citrus spp. in southern Iran based on RAPD-PCR," Journal of Pure and Applied Microbiology, vol. 9, no. 1, pp. 473-482, 2015.

[19] N. Kakvan, H. Zamanizadeh, B. Morid, H. Taheri, and S. Hajmansor, "Study on pathogenic and genetic diversity of Alternaria alternata isolated from citrus hybrids of Iran, based on RAPD-PCR technique," European Journal of Experimental Biology, vol. 2, no. 3, pp. 570-576, 2012.

[20] T. Peever, A. Ibañez, K. Akimitsu, and L. W. Timmer, "Worldwide phylogeography of the citrus brown spot pathogen, Alternaria alternata," Phytopathology, vol. 92, no. 7, pp. 794-802, 2002.

[21] F. Dini-Andreote, V. C. Pietrobon, F. D. Andreote, A. S. Romão, M. B. Spósito, and W. L. Araújo, "Genetic variability of Brazilian isolates of Alternaria alternata detected by AFLP and RAPD techniques," Brazilian Journal of Microbiology, vol. 40, no. 3, pp. 670-677, 2009.

[22] P. Bella, G. Ialacci, M. Russo, A. Catara, and V. Catara, "Characterization of Alternaria alternata isolates from tangerine hybrids affected by brown spot in Italy," in II International Symposium on Citrus Biotechnology, vol. 892, pp. 245-250, Catania, Italy, 2009.

[23] A. C. Ferreira Demartelaere, L. C. do Nascimento, C. O. Marinho et al., "Diversity among Isolates of the Tangerine Pathotype of Alternaria alternata," American Journal of Plant Sciences, vol. 9, no. 2, pp. 196-215, 2018.

[24] A. Niazmand, M. Rahmani, and G. Najafipour, "Evaluation of genetic variation of the causal agent of leaf spot of citrus (Alternaria sp.) isolates based on RFLP-IGS," Journal of Microbial World, vol. 6, no. 2, pp. 117-131, 2013.

[25] H. Budak, R. C. Shearman, I. Parmaksiz, R. E. Gaussoin, T. P. Riordan, and I. Dweikat, "Molecular characterization of buffa- lograss germplasm using sequence-related amplified polymorphism markers," Theoretical and applied genetics, vol. 108, no. 2, pp. 328-334, 2004.

[26] G. Li and C. F. Quiros, "Sequence-related amplified polymorphism (SRAP), a new marker system based on a simple PCR reaction: its application to mapping and gene tagging in Brassica," Theoretical and Applied Genetics, vol. 103, no. 2-3, pp. 455-461, 2001.

[27] S.-J. Sun, W. Gao, S.-Q. Lin, J. Zhu, B. G. Xie, and Z. B. Lin, "Analysis of genetic diversity in Ganoderma population with a novel molecular marker SRAP," Applied Microbiology and Biotechnology, vol. 72, no. 3, pp. 537-543, 2006.

[28] Z. Li, Y. Wang, Y. Chen, J. Zhang, and W. G. D. Fernando, "Genetic diversity and differentiation of Sclerotinia sclerotiorum populations in sunflower," Phytoparasitica, vol. 37, no. 1, pp. 77-85, 2009.

[29] L. Tang, Y. Xiao, L. Li, Q. Guo, and Y. Bian, "Analysis of genetic diversity among Chinese Auricularia auricula cultivars using combined ISSR and SRAP markers," Current Microbiology, vol. 61, no. 2, pp. 132-140, 2010.

[30] L. -Z. Fu, H. Y. Zhang, X. Q. Wu et al., "Evaluation of genetic diversity in Lentinula edodes strains using RAPD, ISSR and SRAP markers," World Journal of Microbiology and Biotechnology, vol. 26, no. 4, pp. 709-716, 2010.

[31] D. Ma, G. Yang, L. Mu, and Y. Song, "Application of SRAP in the genetic diversity of Tricholoma matsutake in northeastern China," African Journal of Biotechnology, vol. 9, no. 38, pp. 6244-6250, 2010.

[32] F. J. Yao, L. X. Lu, P. Wang et al., "Development of a molecular marker for fruiting body pattern in Auricularia auriculajudae," Mycobiology, vol. 46, no. 1, pp. 72-78, 2018.

[33] A. Tripathi and S. C. Dubey, "Sequence-related amplified polymorphism-PCR analysis for genetic diversity in Rhizoctonia solani populations infecting pulse crops in different agroecological regions of India," Plant Pathology Journal (Faisalabad), vol. 14, no. 4, pp. 234-241, 2015.

[34] A. Longya, S. Talumphai, and C. Jantasuriyarat, "Morphological characterization and genetic diversity of rice blast fungus, Pyricularia oryzae, from Thailand using ISSR and SRAP markers," Journal of Fungi, vol. 6, no. 1, p. 38, 2020.

[35] J. H. C. Woudenberg, N. A. van der Merwe, Ž. Jurjević, J. Z. Groenewald, and P. W. Crous, "Diversity and movement of indoor Alternaria alternata across the mainland USA," Fungal Genetics and Biology, vol. 81, pp. 62-72, 2015.

[36] M. Lengia, A. Niazmanda, and M. Kianoushb, "Genetic differences in Alternaria alternata isolates associated with brown spot in tangerine cultivars," Science Asia, vol. 40, 2014.

[37] I. Nemsa, M. Hernández, A. Lacasa et al., "Pathogenicity of Alternaria alternata on fruits and leaves of 'Fortune' mandarin (Citrus clementina $\times$ Citrus tangerina)," Canadian journal of plant pathology, vol. 34, no. 2, pp. 195-202, 2012.

[38] J. C. Rang, P. W. Crous, G. R. A. Mchau, M. Serdani, and S. M. Song, "Phylogenetic analysis of Alternaria spp. associated with apple core rot and citrus black rot in South Africa," Mycological research, vol. 106, no. 10, pp. 1151-1162, 2002.

[39] A. D. Armitage, D. J. Barbara, R. J. Harrison et al., "Discrete lineages within Alternaria alternata species group: Identification using new highly variable loci and support from morphological characters," Fungal Biology, vol. 119, no. 11, pp. 9941006, 2015. 
[40] J. E. Stewart, L. W. Timmer, C. B. Lawrence, B. M. Pryor, and T. L. Peever, "Discord between morphological and phylogenetic species boundaries: incomplete lineage sorting and recombination results in fuzzy species boundaries in an asexual fungal pathogen," BMC Evolutionary Biology, vol. 14, no. 1, p. 38, 2014.

[41] M. Andrew, T. Peever, and B. M. Pryor, "An expanded multilocus phylogeny does not resolve morphological species within the small-sporedAlternariaspecies complex," Mycologia, vol. 101, no. 1, pp. 95-109, 2009.

[42] A. Ennouari, V. Sanchis, M. Rahouti, and A. Zinedine, "Isolation and molecular identification of mycotoxin producing fungi in durum wheat from Morocco," Journal of Materials and Environmental Science, vol. 9, pp. 1470-1479, 2018.

[43] M. Chenaoui, M. Amar, O. Benkhemmar, A. El Aissami, M. Arahou, and L. Rhazi, "Isolation and characterization of fungi from sugar beet roots samples collected from Morocco," Journal of Materials and Environmental Sciences, vol. 8, no. 11, pp. 3962-3967, 2017.

[44] S. Roussos, N. Zaouia, G. Salih et al., "Characterization of filamentous fungi isolated from Moroccan olive and olive cake: toxinogenic potential of Aspergillus strains," Molecular nutrition \& food research, vol. 50, no. 6, pp. 500-506, 2006.

[45] L. da Cruz Cabral, M. Rodriguero, S. Stenglein, K. Fog Nielsen, and A. Patriarca, "Characterization of small-spored Alternaria from Argentinean crops through a polyphasic approach," International Journal of Food Microbiology, vol. 257, pp. 206-215, 2017.

[46] N. Saitou and M. Nei, "The neighbor-joining method: a new method for reconstructing phylogenetic trees," Molecular Biology and Evolution, vol. 4, no. 4, pp. 406-425, 1987.

[47] S. Kumar, G. Stecher, M. Li, C. Knyaz, and K. Tamura, "MEGA $\mathrm{X}$ : molecular evolutionary genetics analysis across computing platforms," Molecular Biology and Evolution, vol. 35, no. 6, pp. 1547-1549, 2018.

[48] I. Roldàn-Ruiz, J. Dendauw, E. Van Bockstaele, A. Depicker, and M. de Loose, "AFLP markers reveal high polymorphic rates in ryegrasses (Lolium spp.)," Molecular breeding, vol. 6, no. 2, pp. 125-134, 2000.

[49] R. Peakall and P. E. Smouse, "GENALEX 6: genetic analysis in Excel. Population genetic software for teaching and research," Molecular Ecology Notes, vol. 6, no. 1, pp. 288-295, 2006.

[50] L. Excoffier, P. E. Smouse, and J. M. Quattro, "Analysis of molecular variance inferred from metric distances among DNA haplotypes: application to human mitochondrial DNA restriction data," Genetics, vol. 131, no. 2, pp. 479-491, 1992.

[51] X. Perrier and J. Jacquemoud-Collet, DARwin software, Cirad, Montpellier, France, 5 edn edition, 2006, http://darwin.cirad .fr/darwin.

[52] J. K. Pritchard, M. Stephens, and P. Donnelly, "Inference of population structure using multilocus genotype data," Genetics, vol. 155, no. 2, pp. 945-959, 2000.

[53] G. Evanno, S. Regnaut, and J. Goudet, "Detecting the number of clusters of individuals using the software STRUCTURE: a simulation study," Molecular ecology, vol. 14, no. 8, pp. 2611-2620, 2005.

[54] J. Mbasani-Mansi, M. Ennami, F. Z. Briache et al., "Characterization of genetic diversity and population structure of Moroccan lentil cultivars and landraces using molecular markers," Physiology and Molecular Biology of Plants, vol. 25, no. 4, pp. 965-974, 2019.
[55] G. Li, M. V. PB, C. F. Quiros, and S. B. Andersen, "SRAP molecular marker technology in plant science," Plant breeding from laboratories to fields, pp. 23-43, 2013.

[56] M. Ennami, F. Z. Briache, J. M. Mansi et al., "Genetic diversity of Moroccan Orobanche crenata populations revealed by sequence-related amplified polymorphism markers," The Journal of Agricultural Science, vol. 9, no. 4, pp. 164-175, 2017.

[57] Q. Xu, J. Zheng, H. Nie, Q. Wang, and X. Yan, "Genetic diversity and population structure ofMeretrix petechialisin China revealed by sequence-related amplified polymorphism markers," PeerJ, vol. 8, article e8723, 2020.

[58] B. Tang, K. Zhou, D. Song, G. Yang, and A. Dai, "Molecular systematics of the Asian mitten crabs, genus Eriocheir (Crustacea: Brachyura)," Molecular Phylogenetics and Evolution, vol. 29, no. 2, pp. 309-316, 2003.

[59] W.-G. Xie, X. Q. Zhang, H. W. Cai, W. Liu, and Y. Peng, "Genetic diversity analysis and transferability of cereal ESTSSR markers to orchardgrass (Dactylis glomerata L.)," Biochemical systematics and ecology, vol. 38, no. 4, pp. 740-749, 2010.

[60] W. Pusz, "Morpho-physiological and molecular analyses of Alternaria alternata isolated from seeds of Amaranthus," Phytopathologia, vol. 54, pp. 5-14, 2009.

[61] Y. Bashan, H. Levanony, and R. Or, "Wind dispersal of Alternaria alternata, a cause of leaf blight of cotton," Journal of Phytopathology, vol. 133, no. 3, pp. 225-238, 1991.

[62] S. Bagherabadi, D. Zafari, and M. Soleimani, "Genetic diversity of Alternaria alternata isolates causing potato brown leaf spot, using ISSR markers in Iran," Journal of Plant Pathology \& Microbiology, vol. 6, no. 7, pp. 1-6, 2015.

[63] J. H. Leiminger, H. J. Auinger, M. Wenig, G. Bahnweg, and H. Hausladen, "Genetic variability among Alternaria solani isolates from potatoes in Southern Germany based on RAPD-profiles," Journal of Plant Diseases and Protection, vol. 120, no. 4, pp. 164-172, 2013.

[64] C. H. Bock, P. H. Thrall, and J. J. Burdon, "Genetic structure of populations of Alternaria brassicicola suggests the occurrence of sexual recombination," Mycological Research, vol. 109, no. 2, pp. 227-236, 2005.

[65] L. Guo, L. Xu, W. H. Zheng, and K. D. Hyde, "Genetic variation of Alternaria alternata, an endophytic fungus isolated from Pinus tabulaeformis as determined by random amplified microsatelites (RAMS)," Fungal Diversity, 2004.

[66] J. Meng, W. Zhu, M. He et al., "High genotype diversity and lack of isolation by distance in the Alternaria solani populations from China," Plant pathology, vol. 64, no. 2, pp. 434$441,2015$. 